\title{
Effects of massage as a recuperative technique on autonomic modulation of heart rate and cardiorespiratory parameters: a study protocol for a randomized clinical trial
}

Nilton Mantovani Junior ${ }^{1}$, Eduardo Pizzo Junior ${ }^{2}$, Malu dos Santos Siqueira ${ }^{1}$, Allysiê Priscilla de Souza Cavina ${ }^{1}$, Carlos Marcelo Pastre ${ }^{1,3}$ and Franciele Marques Vanderlei ${ }^{1,3^{*}}$ (D)

\begin{abstract}
Background: Recuperative techniques have been used to anticipate and potentiate recovery. The massage is one of the most widely used in sports. Among the ways to demonstrate the recovery of the organism is the resumption of autonomic modulation of heart rate, which can be analyzed in situations that cause disturbances in the behavior of the cardiovascular system with the objective of verifying the responsiveness of the autonomic nervous system (ANS). Recovery can be assessed through heart rate variability (HRV) which analyzes the oscillations in consecutive heartbeats, thus allowing an important non-invasive alternative for the study of modulation of the ANS. The objective of the study will be to measure the effects of massage as a recuperative technique on the autonomic modulation of heart rate and cardiorespiratory parameters at different moments of application.
\end{abstract}

Methods: This is a randomized, cross-over clinical trial. Forty men aged 18 to 30 years, healthy and physically active according to the International Physical Activity Questionnaire will participate in the study. Participants will be randomized into groups, which will perform the five interventions of the study at randomized moments, one intervention per session: Intervention 1: control; Intervention 2: participants will receive the massage protocol; Intervention 3: performance of the stress protocol; Intervention 4: participants will perform the stress protocol and immediately after receive the massage; Intervention 5: participants will perform the stress protocol and $1 \mathrm{~h}$ after conclusion of the protocol will receive the massage. The sessions will occur with an interval of 1 week between them and, due to the technique used, blinding participants and therapists is not possible. The primary outcome measure is HRV that will be measured $2 \mathrm{~h}$ after the conclusion of each intervention, and secondary outcome measures, which include heart rate, respiratory rate, blood pressure, oxygen saturation, and individual touch perception, will be measured at specific moments in the course of each intervention.

Discussion: The implementation and use of this standardized protocol should provide important and reliable information regarding the use of massage in post-exercise recovery, with the identification of its effects on the ANS and the best timing and form of massage application. The data obtained in the present study will provide subsidies for the best management of application of the technique in sports clinical practice, considering periods of training and, mainly, of competitions.

(Continued on next page)

\footnotetext{
* Correspondence: franmvanderlei@gmail.com

'Postgraduate Program in Physiotherapy, Universidade Estadual Paulista

(FCT/UNESP), Presidente Prudente, São Paulo, Brazil

${ }^{3}$ Department of Physiotherapy, Universidade Estadual Paulista (FCT/UNESP),

Presidente Prudente, São Paulo, Brazil

Full list of author information is available at the end of the article
}

(c) The Author(s). 2018 Open Access This article is distributed under the terms of the Creative Commons Attribution 4.0 International License (http://creativecommons.org/licenses/by/4.0/), which permits unrestricted use, distribution, and reproduction in any medium, provided you give appropriate credit to the original author(s) and the source, provide a link to the Creative Commons license, and indicate if changes were made. The Creative Commons Public Domain Dedication waiver (http://creativecommons.org/publicdomain/zero/1.0/) applies to the data made available in this article, unless otherwise stated. 
(Continued from previous page)

Trial registration: ClinicalTrials.gov, ID:NCT03094676. Pre-results. 12 March 2018.

Keywords: Autonomic nervous system, Massage, Recovery of function, Heart rate

\section{Background}

Training in its simplest form represents acute challenges to the body intended to optimize chronic improvements in physiological capabilities [1]. The success of the processes of performance improvement and injury prevention depends on the quality of the transition between the physical training stimuli, in addition to the systematization of the exercise prescription. In this sense, an adequate recovery becomes an important aspect of any conditioning program, both for athletes, technicians, and for several health-related professionals [1].

Physical exercise can be a stressor mechanism to body systems, promoting several organic modifications, and recovery processes are commonly employed in the sense of restoring the systems to their basal condition [1]. To accelerate the recovery process after physical exercise, specific techniques are used, and early recovery is considered fundamental for performance, especially within the sporting scene [2]. Of these techniques, massage, consisting of the mechanical manipulation of the corporal tissues [2], stands out, being considered the most commonly used technique in the sports field, both in training and competition periods [3].

Clinical, functional, and metabolic modifications are already described in the relevant literature regarding the effectiveness of massage [4-9]. It is believed that the massage technique is beneficial in reducing muscle pain, by relieving muscle tension and edema as exposed by Hunter et al. [10], stimulating the metabolic clearance of blood lactate and creatine kinase as proposed by Smith et al. [11], and promoting improvement in flexibility and range of motion [6].

However, the physiological adaptations promoted by massage can also be monitored through autonomic nervous system (ANS) and cardiovascular responses [11]. Studies have shown that relaxing therapeutic modalities, such as massage, have presented favorable results for recovery in cardiovascular markers, such as a decrease in heart rate and blood pressure in the post-exercise period [12-14].

In relation to the markers of autonomic recovery, massage has also demonstrated positive results in the recovery capacity. Arroyo-Morales et al. [15] performed a 40-min massage on the whole body of the participants after a three-sprint Wingate exercise protocol of $30 \mathrm{~s}$ separated by a 3-min interval and observed that massage was favorable for the recovery of the heart rate variability (HRV) indices to baseline.
However, in the study of Arroyo-Morales et al. [15] some gaps can be identified in the literature. Before the massage technique, the participants performed 15 min of active and passive recovery, the massage technique had five different modalities of tissue manipulation applied in regions that were not protagonists during the stress, with prolonged duration and applied only at one moment. These details in the design of the study may influence the responses found in the recovery of autonomic modulation of heart rate, especially considering practical applications. However, the main gap addressed by the present study protocol is related to the moment of application of massage as a recuperative technique. To study the optimal timing of the technique seems interesting since various sports modalities participate in several competitions throughout the day and, thus, it is necessary to understand the best moment of application of the recuperative technique to guarantee the best performance of the athletes.

The recovery of autonomic modulation of heart rate has been considered an important global marker of athlete recovery. Ihsan et al. [16] reported that the return of HRV values is a good indicator for exercise dynamics to be applied in training or in competitions. In addition, although massage is widely used as a recuperative technique, there are gaps in the literature regarding the effectiveness of massage in the autonomic modulation of heart rate and cardiorespiratory parameters; and especially in relation to the best moment of application. It is unclear whether performance of the massage technique has a beneficial effect on HRV both to anticipate its recovery and potentiate the effects of recovery depending on the moment of its application.

The present study is a randomized clinical trial aimed at investigating the effects of massage as a recuperative technique on the recovery of autonomic modulation of heart rate and cardiorespiratory parameters in physically active young people comparing two distinct scenarios: (1) immediately after stress in order to investigate if the technique anticipates the recovery of the ANS, and (2) immediately after the recovery moment of the ANS in order to investigate whether the technique potentiates the recovery of the ANS.

\section{Methods \\ Study design}

A randomized, cross-over, controlled clinical trial will be conducted at the Center for Studies and Care in 
Physiotherapy and Rehabilitation of the Universidade Estadual Paulista (FCT/UNESP), Presidente Prudente, São Paulo, Brazil. The study design is illustrated in Fig. 1. The study protocol follows the SPIRIT 2013 Checklist (Standard Protocol Items: Recommendations for International Trials) (Additional file 1) and TIDieR (Template for Intervention Description and Replication) so that the information and quality of the reports of the interventions are well described. The trial was registered at ClinicalTrials.gov (NCT03094676).

\section{Participants}

A total of 40 participants will be recruited at the local university (Universidade Estadual Paulista) through online advertising and approaching participants by telephone, SMS, and social networks, from January 2018 to April 2018. Participants will be considered eligible if they are apparently healthy, male, aged between 18 and 30 years, and have a Body Mass Index (BMI) classified as normal (between 18.5 and $25 \mathrm{~kg} \cdot \mathrm{m}^{2}$ ) according to the World Health Organization [17]. In addition, participants who have at least one of the following characteristics will not be included: smokers, use of medications that influence autonomic modulation of heart rate, alcoholics, known metabolic and/or endocrine disorders, individuals with musculotendinous injuries in the region of the lower limbs and trunk in the previous 6 months, and sedentary, insufficiently active, and very active individuals according to the International Physical Activity Questionnaire (IPAQ) [18]. With the exception of assessing the level of physical activity that will be carried out through the application of the IPAQ, the principal investigator will determine whether potential participants meet the eligibility criteria during an initial interview. Ethical approval has been granted by the Human Ethics Committee of the São Paulo State University (CAAE: 57584116.6.0000.5402).

\section{Analysis population}

The criteria that define the exclusion of the participant in the final analysis of the data will be: intercurrences during the execution of the protocols that prevent their continuity, absence from more than $80 \%$ of the proposed sessions, and capture errors in the RR intervals.

\section{Randomization}

Participants who meet the eligibility criteria and sign the consent form will be randomized, using simple randomization, for logistic reasons into five groups and the groups will be randomized into the different interventions of the study to determine the order of accomplishment. In order to guarantee the hidden allocation of the participants in the groups and the randomization of the study interventions, a researcher not involved in the recruitment will be responsible for this procedure using electronic software (Microsoft Office Excel). This researcher will be instructed not to previously inform the participants or other researchers about the procedures that will be performed in each session. The following figure presents the schematization of the aforementioned randomization processes (Fig. 2).

\section{Design description}

The study will be conducted in five interventions (Intervention 1 (I1); Intervention 2 (I2); Intervention 3 (I3); Intervention 4 (I4); Intervention 5 (I5)), and the groups will be randomized to perform these interventions at several moments, with a 1-week interval between interventions. Data collection will always be performed at the same period of day and in air-conditioned environments.

\section{Procedures \\ Study interventions}

The description of the interventions is as follows:

1. Intervention 1 (I1): the HRV behavior of the participant will be evaluated without exposure to any recovery technique or any type of stress. The follow-up period will be $2 \mathrm{~h}$

2. Intervention 2 (I2): the HRV behavior of the participant will be evaluated before the application of the massage technique. Evaluations will be performed $2 \mathrm{~h}$ after massage application

3. Intervention 3 (I3): the HRV behavior of the participant will be evaluated before the implementation of the stress protocol. The autonomic modulation of heart rate will be evaluated $2 \mathrm{~h}$ after the end of the stress protocol

4. Intervention 4 (I4): the HRV behavior of the participant will be evaluated before the stress protocol, followed immediately by the massage technique, as well as $2 \mathrm{~h}$ after the completion of the massage in order to observe if HRV is anticipated

5. Intervention 5 (I5): the HRV behavior of the participant will be evaluated before the stress protocol, and the massage technique will be applied at the exact moment of ANS recovery, determined by the study of Almeida et al. [11] who used the same stress protocol, and posteriorly there will be follow up for $2 \mathrm{~h}$ in order to see if there is potentiation of HRV recovery

The first three interventions of the study (I1, I2, and I3) will be performed to establish the basal behavior of the study variables and/or before the two different stimuli (massage and stress), and for possible explanations and discussion of the study. 


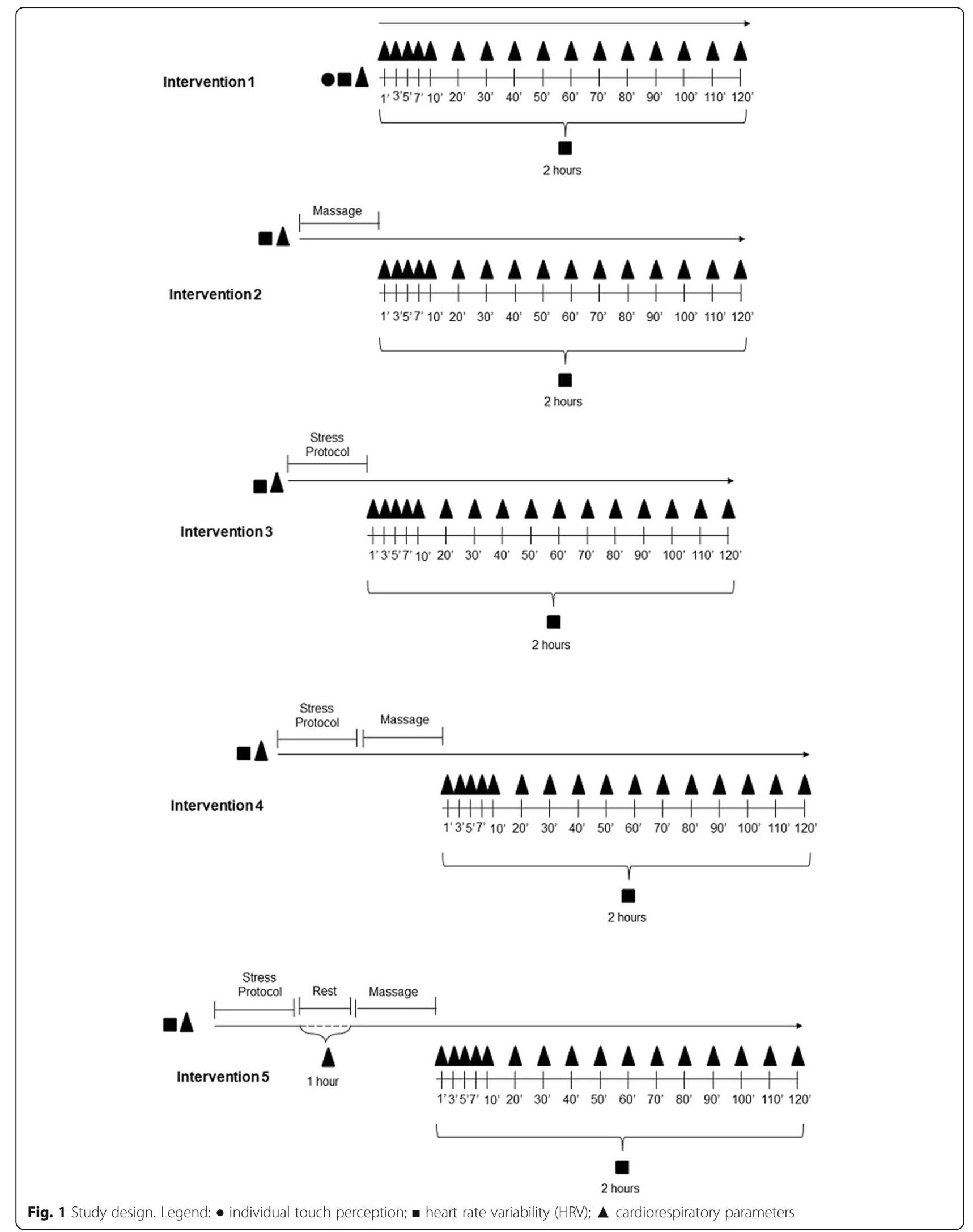



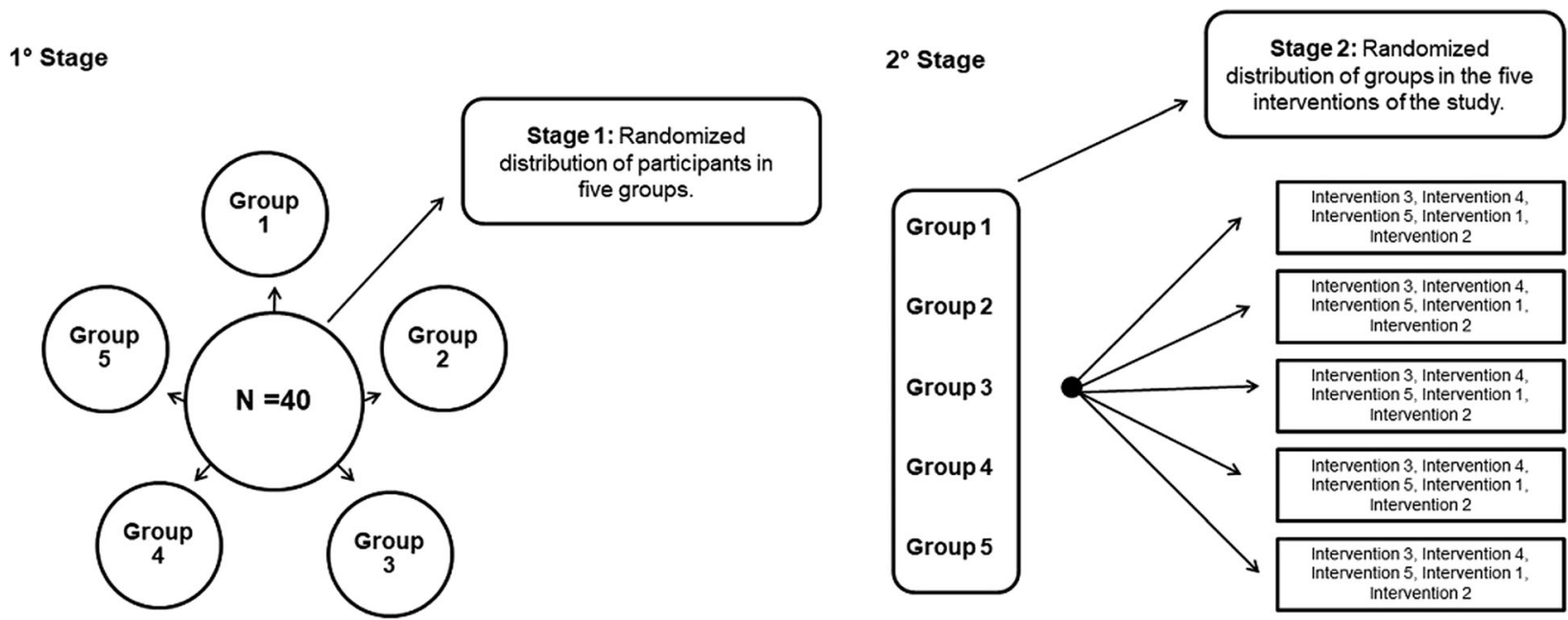

Fig. 2 Schematization of the randomization processes

In Interventions 4 and 5, analysis of the effects of massage on post-exercise recovery, and the comparison of the effects of massage when performed immediately after stress or $1 \mathrm{~h}$ after stress, will be performed.

It is emphasized that at I5 the massage will be applied $60 \mathrm{~min}$ after the end of the stress protocol, as this was the exact time identified in the study by Almeida et al. [11] for the recovery of the internal control functions of the body after the same stress protocol as used in the present study.

\section{Procedure details}

\section{Stress protocol}

Participants will be submitted to a stress protocol consisting of a jumping program and a maximum short-term cycling test [11]. The jumping program consists of 10 sets of 10 jumps with a 1-min interval between sets. During the jump, participants will be instructed to place their hands on their hips and during the jump landing to flex their knees at $90^{\circ}$ in order to avoid compensations. After the jump, the participants will have $1 \mathrm{~min}$ of rest and then perform the Wingate anaerobic test protocol, which will be performed on a cycle ergometer Biotec 2100 (Cefise, Nova Odessa, Brazil). The test consists of a 5-min warm-up and the test itself. During warm-up the participant will pedal at a speed of 60 to $90 \mathrm{rpm}$ with a fixed load of $1.0 \mathrm{~kg}$, and in the second and fourth minutes the participant will be required to perform a sprint, reaching the maximum possible speed according to individual perception. After the 5-min warm-up the anaerobic test will be performed, consisting of maximum pedaling for $30 \mathrm{~s}$ with a stipulated load of 0.075 $\mathrm{kp} \cdot \mathrm{kg}^{-1}$ of the participant's body mass. During the sprints and test, verbal stimuli will be provided to stimulate maximum performance.
This stress protocol was chosen due to the study of Almeida et al. [11] which investigated the protocol and concluded that it is effective in triggering derangements in the ANS. Immediately after completion of the protocol, participants will be directed to a stretcher, where they will lie down to perform the massage immediately after stress (I4) or $1 \mathrm{~h}$ after stress (I5), or to remain at rest (I1, I2, and I3), and then be followed up for $2 \mathrm{~h}$ to capture the RR intervals.

It is worth mentioning that after the stress protocol all participants will be required to drink $180 \mathrm{ml}$ of water in order to standardize hydration and avoid the influence of blood volume on the results of the present clinical trial.

\section{Massage protocol}

According to a recent systematic review with meta-analysis [19], the effects of massage seem to be better when it is applied for between 5 and $12 \mathrm{~min}$. Thus, the massage in the present protocol will have a total of 12 min duration, being 6 min on the anterior region of the thigh ( 3 min for each limb) and $6 \mathrm{~min}$ on the posterior region of the trunk. The choice of these anatomical sites was due to the effort required by the stress protocol and location of the preganglionic neurons of the ANS, respectively.

For massage on the anterior thigh (quadriceps femoris muscle) the participant will be placed in the dorsal decubitus and the massage initiated on the dominant limb and then the non-dominant limb, and posteriorly, in the ventral decubitus position, massage will be performed on the trunk (paravertebral muscles). The techniques of surface and deep slip will be used, the latter being presented at two intensities, moderate or intense, being gradually increased. The massage will be performed towards the muscle fibers, from distal to proximal and following the lymphatic flow. 
Table 1 Massage protocol for the anterior thigh region and posterior trunk region

\begin{tabular}{llllll}
\hline $\begin{array}{l}\text { Anatomical } \\
\text { site }\end{array}$ & Slip & Pressure & Rhythm & $\begin{array}{l}\text { Time } \\
\text { (seconds) }\end{array}$ & $\begin{array}{l}\text { Total slips } \\
\text { per } \\
\text { technique }\end{array}$ \\
\hline $\begin{array}{l}\text { Anterior } \\
\text { thigh }\end{array}$ & Surface & Light & 1 slip every 2 s & 60 & 30 \\
& Deep 1 & Moderate & 1 slip every 2 s & 60 & 30 \\
& Deep 2 & Intense & 1 slip every 2 s & 60 & 30 \\
Posterior & Surface & Light & 1 slip every 2 s & 120 & 60 \\
trunk & Deep 1 & Moderate & 1 slip every 2 s & 120 & 60 \\
& Deep 2 & Intense & 1 slip every 2 s & 120 & 60 \\
\hline
\end{tabular}

The massage will be performed by three physiotherapists specializing in sports physiotherapy, previously trained by a sports physiotherapist with 10 years' experience in sports massage.

A pilot study will be conducted for the training of the physiotherapists who will apply the massage in a standardized manner regarding the intensity, rhythm, form of application of massage, and application dynamics through data collection. The physiotherapists will be required to present excellent correlations between them in order to be eligible to perform the technique.

The massage will have the rhythm: $1 \mathrm{~s}$ of slip and $1 \mathrm{~s}$ for return of the hand to the initial position, totaling $2 \mathrm{~s}$ of slip (Table 1). The rhythm of the massage will be controlled by an electronic metronome that will only be used by the therapists during performance of the technique.

Besides standardization of the intensity and rhythm of the massage performed by the physiotherapist, in order not to cause discomfort and possible pressure variations in the application of the technique, participants will be required to report their level of comfort from a scale that considers the technique as "light," "moderate," or "intense," corresponding, respectively, to surface slip, deep 1 slip, and deep 2 slip. Details of the massage protocol can be seen in Table 1 .

\section{Participant timeline}

The time schedule of enrollment, interventions, and assessments is outlined in Fig. 3. Recruitment of study subjects started in April 2018.

\begin{tabular}{|c|c|c|c|c|c|}
\hline \multirow[b]{3}{*}{ TIMEPOINT } & \multicolumn{5}{|c|}{ Study Period } \\
\hline & \multirow{2}{*}{$\begin{array}{c}\text { Enrolment } \\
-t_{1} \\
\end{array}$} & \multirow{2}{*}{$\begin{array}{c}\text { Allocation } \\
0 \\
\end{array}$} & \multicolumn{2}{|c|}{$\begin{array}{c}\text { Post- } \\
\text { allocation }\end{array}$} & \multirow{2}{*}{$\begin{array}{c}\text { Close-out } \\
t_{x} \\
\end{array}$} \\
\hline & & & $\begin{array}{c}1 \\
\text { hour }\end{array}$ & $\begin{array}{c}2 \\
\text { hour }\end{array}$ & \\
\hline \multicolumn{6}{|l|}{ ENROLMENT: } \\
\hline \multirow{3}{*}{$\begin{array}{l}\text { Eligibility screen } \\
\text { Informed consent } \\
\text { Allocation }\end{array}$} & $\mathrm{X}$ & & & & \\
\hline & $\mathrm{X}$ & & & & \\
\hline & & $\mathrm{X}$ & & & \\
\hline \multicolumn{6}{|l|}{ INTERVENTIONS: } \\
\hline \multirow{2}{*}{$\begin{array}{l}\text { [Intervention 1] } \\
\text { [Intervention 2] }\end{array}$} & & & $\mathrm{X}$ & $\mathrm{X}$ & \\
\hline & & & $\mathrm{x}$ & $\mathrm{X}$ & \\
\hline \multirow[t]{2}{*}{ [Intervention 3] } & & & $\mathrm{X}$ & $\mathrm{X}$ & \\
\hline & & & $\mathrm{x}$ & $\mathrm{x}$ & \\
\hline $\begin{array}{l}\text { [Intervention 4] } \\
\text { [Intervention 5] }\end{array}$ & & & $\mathrm{X}$ & $\mathrm{X}$ & \\
\hline \multicolumn{6}{|l|}{ ASSESSMENTS: } \\
\hline [Baseline data] & $\mathrm{X}$ & $\mathrm{X}$ & & & $\mathrm{X}$ \\
\hline \multirow{2}{*}{$\begin{array}{r}\text { [Change of HRV] } \\
\text { [Change of } \\
\text { cardiorespiratory } \\
\text { parameters] }\end{array}$} & $\mathrm{X}$ & $\mathrm{X}$ & $\mathrm{x}$ & $\mathrm{X}$ & $\mathrm{X}$ \\
\hline & $\mathrm{X}$ & $\mathrm{X}$ & $\mathrm{X}$ & $\mathrm{X}$ & $\mathrm{X}$ \\
\hline
\end{tabular}

Fig. 3 Content for the schedule of enrollment, interventions, and assessments 


\section{Outcomes}

The primary outcome will be the evaluation of autonomic modulation of heart rate by means of HRV. Secondary outcomes are cardiorespiratory parameters (blood pressure, heart rate, respiratory rate, and oxygen saturation) and individual touch perception. Evaluations will be performed by the same independent trained assessors throughout the study.

\section{Primary outcome}

HRV will be used as the primary outcome as it is an important overall marker of post-exercise recovery [16]. The HRV analysis will be performed from the series of RR intervals captured by the cardiofrequency meter Polar Electro Oy - model V800, and linear methods analyzed in the time domain and frequency domain, and Poincaré plot. All HRV indices will be obtained through the software Kubios HRV - version 2.0 [20].

For this analysis, the time series of $R R$ intervals will initially be subjected to digital filtering using the software Kubios HRV - version 2.0, supplemented by manual filtering, to eliminate premature ectopic beats and artifacts, and only series with more than $95 \%$ of sinus beats will be included in the study [20]. Through visual analysis of the time series, the absence of ectopic artifacts or beats that can interfere in the HRV analysis will be observed.

During the recovery period, the evaluated moments will be: R1 (initial 5 min of rest before performing the interventions), R2 (initial $5 \mathrm{~min}$ of recovery), R3 (fifth to 10 th minutes of recovery), R4 (10th to 15 th minutes of recovery), R5 (20th to 25th minutes of recovery), R6 (30th to 35th minutes of recovery), R7 (40th to 45th minutes of recovery), R8 (50th to 55th minutes of recovery), R9 (60th to 65th minutes of recovery), R10 (70th to 75 th minutes of recovery), R11 (90th to 95th minutes of recovery), and R12 (115th to 120th minutes of recovery). It is worth mentioning that 256 consecutive $R R$ intervals will be obtained at these moments [21].

HRV indices in the time domain (rMSSD and SDNN), frequency domain (low-frequency spectral component (LF) and high-frequency spectral component (HF)), and the Poincaré plot (SD1 and SD2) will be evaluated [22].

In the time domain, the rMSSD Index corresponds to the square root of the square mean of the differences between the adjacent normal RR intervals in a time interval expressed in milliseconds and evaluates the behavior of the parasympathetic autonomic modulation [22], while the SDNN Index represents the standard deviation of all normal RR intervals recorded in a time interval, expressed in milliseconds, and is considered a measure of global variability, that is, it evaluates both sympathetic and parasympathetic modulation [22].
In the frequency domain the low-frequency spectral component (LF - frequency between 0.04 and $0.15 \mathrm{~Hz}$ ) is considered an index that evaluates sympathetic and parasympathetic behavior [22, 23], while the high-frequency spectral component (HF - frequency between 0.15 and $0.4 \mathrm{~Hz}$ ) is a marker of vagal modulation [22, 23]. The spectral analysis will be calculated from a tachograph using the fast Fourier transform algorithm.

The Poincaré plot is a map of points in Cartesian coordinates constructed from the values of the RR intervals obtained [22]. For quantitative analysis of the plot an ellipse will be adjusted to the points of the graph where the indices SD1 and SD2 are obtained. SD1 is an instantaneous index of beat-to-beat variability and represents the parasympathetic modulation [24], while the SD2 Index represents the HRV in long-term records, and reflects the overall variability [24].

\section{Secondary outcomes}

The study will include five measures of secondary outcomes: individual touch perception, which will be collected at baseline of the first randomized intervention, and blood pressure, heart rate, respiratory rate, and oxygen saturation, which will always be collected at baseline and during the $2 \mathrm{~h}$ of recovery at minutes $1,3,5,7,10$, $20,30,40,50,60,70,80,90,100,110$, and 120 . In addition, in 15 these variables will be collected $1 \mathrm{~h}$ prior to the application of the massage at minutes $1,3,5,7$, $10,20,30,40,50$, and 60 .

\section{- Blood Pressure}

$\bigcirc$ Blood pressure will be verified by an indirect method using a stethoscope (Littmann, Saint Paul, MN, USA) and an aneroid sphygmomanometer (Welch Allyn - Tycos, Skaneateles Falls, NY, USA) fixed on the left arm of the volunteers. To avoid errors in determining blood pressure, these measurements will be performed by a single evaluator. The measurements will be performed according to the criteria established by the VII Brazilian Hypertension Guidelines [25]

\section{- Heart rate}

$\bigcirc$ To verify the heart rate, a cardio frequency meter (Polar Electro Oy, Kempele, Finland - model V800) will be used [22]

- Respiratory rate

$\bigcirc$ Respiratory rate measurements will be performed by counting the respiratory incursions for $1 \mathrm{~min}$ without the participant being aware of the process, so that the usual breathing characteristics are not modified [26]

\section{- Oxygen saturation}

$\bigcirc$ Oxygen saturation will be verified by means of a pulse oximeter (Mindray PM-50 Pulse Oximeter, 
China). The pulse oximeter is a device that provides blood saturation readings by evaluating the absorption behavior of oxyhemoglobin and deoxyhemoglobin in relation to red and infrared light lengths [27]

- Questionnaire on individual touch perception $\bigcirc$ The Touch Avoidance Questionnaire [28] is a questionnaire composed of 37 questions that evaluate the experience of the touch received by another person. One question addresses how invasive the touch is from the unknown person and the other question addresses the touch experience by a professional whose profession requires the same touches, such as masseurs. The questionnaire contains 37 questions, and the questions offer the alternatives: "true" and "false" for scoring the touch experience; however, we will only use two adapted questions and the answers will be given on a linear scale equivalent to $10 \mathrm{~cm}$, where 0 is without any discomfort and 10 is extremely uncomfortable

\section{Sample size}

As described above the primary outcome will be the HRV. The sample size calculation was carried out based on the study of Arroyo-Morales et al. [15] in which the SDNN Index of the HRV was selected, since it is an index that expresses the behavior of the ANS in a global way. To establish the sample size, a mean effect of 26.9 and standard deviation of 38.8 were chosen. The level of significance for the sample size is $5 \%$, the power test is $80 \%$, two-tailed test, and $10 \%$ of the total value of $n$ is added to statistically supply the analyses in the case of withdrawals during data collection. The value obtained for the sample size was 33 participants, adding the $10 \%$ gave a sample of 36 volunteers. However, there are other indices besides the SDNN Index within the HRV, and this situation generates an environment where the sample size could be underestimated. In the same sense, due to the new proposal presented by the study, there are no trials in the literature that have the same proposal dynamics, and thus, for safety we will add four volunteers to ensure the statistical analysis of all HRV indices, thus totaling a sample of 40 participants.

\section{Statistical analysis}

For analysis of the data of the population profile, the descriptive statistical method will be used and the results presented as values of means, standard deviations, median, minimum and maximum numbers, and confidence interval. The normality of the data will be evaluated through the Shapiro-Wilk test.

The comparisons of cardiorespiratory parameters and HRV indices between interventions (I1, I2, I3, I4, and I5) and moments (rest (R1) vs recovery moments (R2-R12)), the data are analyzed from the prism of the covariance analysis (ANCOVA), which will be adjusted for the baseline value of the evaluated variable and generated estimated means after such adjustment (extracting the variance explained by the confounding variables). The Levene test will be used to prove the homogeneity of the variances at the created moments, and the Bonferroni post hoc test will be used for comparison. To guarantee homogeneity of data the variable can will be transformed into logarithm.

For analysis of the moments (rest vs recovery moments), repeated measures ANOVA with the Tukey post test for parametric distribution or Friedman test with Dunnett's post test for non-parametric distribution will be used and the analysis of the different groups will be performed by means of one-way ANOVA with the Tukey post test or the Kruskal-Wallis test with Dunnett's post test.

The level of significance will be $p<0.05$ for all tests. The SPSS statistical program (version 13.0) (SPSS Inc., Chicago, IL, USA) will be used for the analyses. Data integrity will be monitored by regularly scrutinizing data files for omissions and errors. Participants will be given an anonymous study ID to protect confidentiality, and only study investigators will have access to the final trial data set.

\section{Discussion}

\section{Potential impact and significance of the study}

This massage protocol was created from recent findings in the literature and its standardization was performed according to the union of the best results found. The implementation and use of this standardized protocol will provide important and reliable information regarding the use of massage in post-exercise recovery, with the identification of its effects on the ANS and the best moment and form of massage application, representing an important advance in the sports field and in clinical practice.

\section{Strengths and limitations of this study}

A strong point of this study is that the protocol created was based on the latest in the literature on the theme. Another strong point of the study is the comparison of the effects of massage when applied at different moments on post-exercise recovery. In addition, its design of a randomized clinical trial of the cross-over type, the easy reproducibility of the protocol from the description of the same, the fact of the massage being performed by three physiotherapists specialized in sports physiotherapy also enhances the study. However, one limitation of this study is the impossibility of blinding the physiotherapists and participants regarding the application of the technique, and although standardized there is no control of the pressure exerted during the massage, only a 
subjective control through the level of comfort of the volunteer with the specific scale application.

\section{Contribution and clinical applicability}

With the accomplishment of this study we will verify which HRV indices demonstrate a significant influence of the massage in post-exercise recovery, and which moment of application presents better recovery after exercise. The data obtained in the present study will provide subsidies for the best management of application of the technique in sports clinical practice, considering periods of training and, mainly, of competitions.

\section{Trial status}

Number Protocol: NCT03094676

Patient recruitment is currently underway.

Study start date: 9 April 2018

Primary completion date: 14 May 2018

Study Completion date: 30 July 2018

\section{Additional file}

Additional file 1: Recommendations for Interventional Trials (SPIRIT), (DOC $120 \mathrm{~kb}$ )

\begin{abstract}
Abbreviations
ANS: Autonomic nervous system; BMI: Body Mass Index; FCT/ UNESP: Universidade Estadual Paulista; HF: High-frequency spectral component; HRV: Heart rate variability; I1: Intervention 1; I2: Intervention 2; 13: Intervention 3: 14: Intervention 4; 15: Intervention 5; IPAQ: International Physical Activity Questionnaire; LF: Low-frequency spectral component; rMSSD: Index corresponds to the square root of the square mean of the differences between the adjacent normal RR intervals in a time interval, expressed in milliseconds; SD1: Instantaneous index of beat-to-beat variability; SD2: Index represents the HRV in long-term records; SDNN: Index represents the standard deviation of all normal RR intervals recorded in a time interval, expressed in milliseconds
\end{abstract}

\section{Acknowledgements}

This study has the financial support of São Paulo Research Foundation FAPESP (grant 2017/20193-9 to EPJ).

\section{Funding}

EPJ was sponsored by São Paulo Research Foundation (FAPESP/ project number 2017/20193-9) to conduct this project.

\section{Authors' contributions}

Contributors EPJ with input from the other investigators conceived and received funding to conduct this study. NMJ, EPZ, MSS, APSC, CMP, and FMV commented on the various versions of this study protocol. NMJ, EPJ, and FMV were involved in the recruitment and data collection. EPJ, APSC, and FMV will conduct the analyses. All authors approved the final manuscript.

Ethics approval and consent to participate

Ethical approval has been granted by the Human Ethics Committee of the São Paulo State University (CAAE: 57584116.6.0000.5402).

\section{Consent for publication}

Not applicable.

\section{Competing interests}

The authors declare that they have no competing interests.

\section{Publisher's Note}

Springer Nature remains neutral with regard to jurisdictional claims in published maps and institutional affiliations.

\section{Author details}

${ }^{1}$ Postgraduate Program in Physiotherapy, Universidade Estadual Paulista (FCT/UNESP), Presidente Prudente, São Paulo, Brazil. ${ }^{2}$ Graduation in Physiotherapy, Universidade Estadual Paulista (FCT/UNESP), Presidente Prudente, São Paulo, Brazil. ${ }^{3}$ Department of Physiotherapy, Universidade Estadual Paulista (FCT/UNESP), Presidente Prudente, São Paulo, Brazil.

Received: 23 March 2018 Accepted: 1 August 2018

Published online: 25 August 2018

\section{References}

1. Bishop PA, Jones E, Woods AK. Recovery from training: a brief review: brief review. J Strength Cond Res. 2008;22(3):1015-24

2. Cafarelli $E$, Flint $F$. The role of massage in preparation for and recovery from exercise. An overview. Sports Med. 1992;14(1):1-9.

3. Best TM, Hunter R, Wilcox A, Hag F. Effectiveness of sports massage for recovery of skeletal muscle from strenuous exercise. Clin J Sport Med. 2008:18(5):446-60

4. Nunes GS, Bender PU, de Menezes FS, Yamashitafuji I, Vargas VZ, Wageck B. Massage therapy decreases pain and perceived fatigue after long-distance ironman triathlon: a randomised trial. J Physiother. 2016;62(2):83-7.

5. Han JH, Kim MJ, Yang HJ, Lee YJ, Sung YH. Effects of therapeutic massage on gait and pain after delayed onset muscle soreness. J Exerc Rehabil. 2014; 10(2):136-40.

6. Forman J, Geertsen L, Rogers ME. Effect of deep stripping massage alone or with eccentric resistance on hamstring length and strength. J Bodyw Mov Ther. 2014;18(1):139-44

7. Hongsuwan C, Eungpinichpong W, Chatchawan U, Junichiro Y. Effects of Thai massage on physical fitness in soccer players. J Phys Ther Sci. 2015; 27(2):505-8

8. Torres R, Ribeiro F, Alberto Duarte J, Cabri JM. Evidence of the physiotherapeutic interventions used currently after exercise-induced muscle damage: systematic review and meta-analysis. Phys Ther Sport. 2012;13(2):101-14

9. Ali Rasooli S, Koushkie Jahromi M, Asadmanesh A, Salesi M. Influence of massage, active and passive recovery on swimming performance and blood lactate. J Sports Med Phys Fitness. 2012;52(2):122-7.

10. Smith LL, Keating MN, Holbert D, Spratt DJ, McCammon MR, Smith SS, et al. The effects of athletic massage on delayed onset muscle soreness, creatine kinase, and neutrophil count: a preliminary report. J Orthop Sports Phys Ther. 1994;19(2):93-9.

11. Almeida AC, Machado AF, Albuquerque MC, Netto LM, Vanderlei FM, Vanderlei LC, et al. The effects of cold water immersion with different dosages (duration and temperature variations) on heart rate variability post-exercise recovery: a randomized controlled trial. J Sci Med Sport. 2016;19(8):676-81

12. Diego MA, Field T. Moderate pressure massage elicits a parasympathetic nervous system response. Int J Neurosci. 2009;119(5):630-8.

13. Ahles TA, Tope DM, Pinkson B, Walch S, Hann D, Whedon M, et al. Massage therapy for patients undergoing autologous bone marrow transplantation. J Pain Symptom Manag. 1999;18(3):157-63.

14. Kubsch SM, Neveau T, Vandertie K. Effect of cutaneous stimulation on pain reduction in emergency department patients. Complement Ther Nurs Midwifery. 2000;6(1):25-32.

15. Arroyo-Morales M, Olea N, Martinez M, Moreno-Lorenzo C, Díaz-Rodrígues L, Hidalgo-Lozano A. Effects of myofascial release after high-intensity exercise: a randomized clinical trial. J Manip Physiol Ther. 2008;31(3):217-23.

16. Ihsan M, Watson $G$, Abbiss CR. What are the physiological mechanisms for post-exercise cold water immersion in the recovery from prolonged endurance and intermittent exercise. Sports Med. 2016:46(8):1095-109.

17. WHO [homepage]. Obesity and overweight: WHO. Available in http://www. who.int/gho/ncd/risk_factors/overweight/en/. Accessed 16 Feb 2018.

18. Matsudo S, Araújo T, Matsudo V, Andrade D, Andrade E, Oliveira LC, et al. Questionário internacional de atividade física(IPAQ): estudo de validade e reprodutibilidade no Brasil. Rev Bras Ativ Fís Saúde. 2001: 6(2):5-18. 
19. Poppendieck W, Wegmann M, Ferrauti A, Kellmann M, Pfeiffer M, Meyer T. Massage and performance recovery: a meta-analytical review. Sports Med. 2016;46(2):183-204.

20. Tarvainen MP, Niskanen JP, Lipponen JA, Ranta-Aho PO, Karjalainen PA. Kubios HRV - heart rate variability analysis software. Comput Methods Prog Biomed. 2014;113(1):210-20.

21. Godoy MF, Takakura IT, Correa PR. Relevância da análise do comportamento dinâmico não-linear (Teoria do Caos) como elemento prognóstico de morbidade e mortalidade em pacientes submetidos à cirurgia de revascularização miocárdica. Arq Ciênc Saúde. 2005;12(4):167-71.

22. Vanderlei LCM, Pastre CM, Hoshi RA, Carvalho TD, Godoy MF. Basic notions of heart rate variability and its clinical applicability. Braz J Cardiovasc Surg. 2009;24(2):205-17.

23. Peçanha T, de Paula-Ribeiro M, Nasario-Junior O, de Lima JR. Post-exercise heart rate variability recovery: a time-frequency analysis. Acta Cardiol. 2013; 68(6):607-13.

24. Hoshi RA, Pastre CM, Vanderlei LC, Godoy MF. Poincaré plot indexes of heart rate variability: relationships with other nonlinear variables. Auton Neurosci. 2013;177(2):271-4.

25. Arterial SD-DdH. VII Diretrizes Brasileiras de Hipertensão Arterial. Arq Bras Cardiol. 2016;107(3):1-103.

26. Silva KN, Martins NC, Silveira JM, Martins NC, Reis GR. Músculos respiratórios: fisiologia, avaliação e protocolos de treinamento. Rev Cereus. 2011;3(2):1-6.

27. Nunes WA, Terzi RGG. Pulse oximeters in the evaluation of oxygen transportation in critical patients. Rev Latino-Am Enfermagem. 1999;7(2):79-85.

28. Vieira Al, Ramos AV, Cavalheiro LM, Almeida P, Nogueira D, Reis E, et al. Reliability and validity of the european portuguese version of the social touch questionnaire. J Nonverbal Behav. 2016;40(4):363-77.

Ready to submit your research? Choose BMC and benefit from:

- fast, convenient online submission

- thorough peer review by experienced researchers in your field

- rapid publication on acceptance

- support for research data, including large and complex data types

- gold Open Access which fosters wider collaboration and increased citations

- maximum visibility for your research: over $100 \mathrm{M}$ website views per year

At $\mathrm{BMC}$, research is always in progress.

Learn more biomedcentral.com/submissions 